\title{
Implementation and evaluation of prognostic representations of the optical diameter of snow in the detailed snowpack model SURFEX/ISBA-Crocus
}

\author{
C.M. Carmagnola ${ }^{1}$, S. Morin ${ }^{1}$, M. Lafaysse ${ }^{1}$, F. Domine ${ }^{2}$, B. Lesaffre ${ }^{1}$, Y.

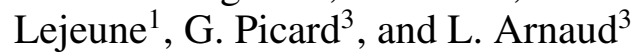 \\ ${ }^{1}$ Météo France - CNRS, CNRM - GAME UMR 3589, Centre d'Études de la Neige, Grenoble, \\ France \\ ${ }^{2}$ Takuvik Joint International Laboratory, CNRS and Université Laval, Québec (QC), Canada \\ ${ }^{3}$ CNRS, UJF Grenoble, LGGE, Grenoble, France \\ Correspondence to: C.M. Carmagnola \\ (carlo.carmagnola@meteo.fr)
}

\section{Abstract.}

Supplementary material including 5 figures. 

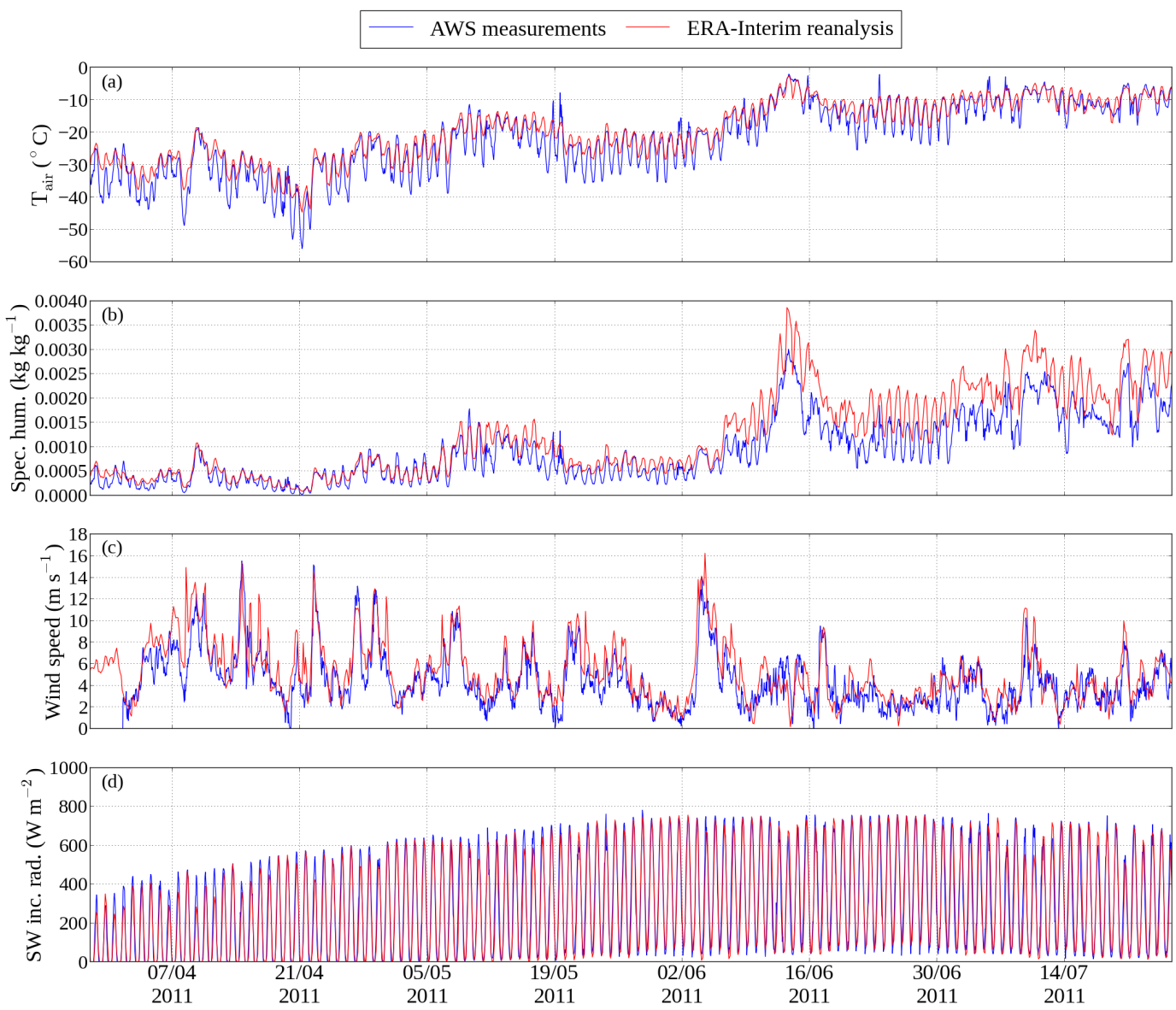

Fig. 1: Comparison between AWS measurements and ERA-Interim reanalysis at Summit during the period April-July 2011. From top to bottom: a) air temperature at $2 \mathrm{~m}$ above snow, b) specific humidity at $2 \mathrm{~m}$ above snow, c) wind speed at $10 \mathrm{~m}$ above snow and d) short-wave incoming radiation. 

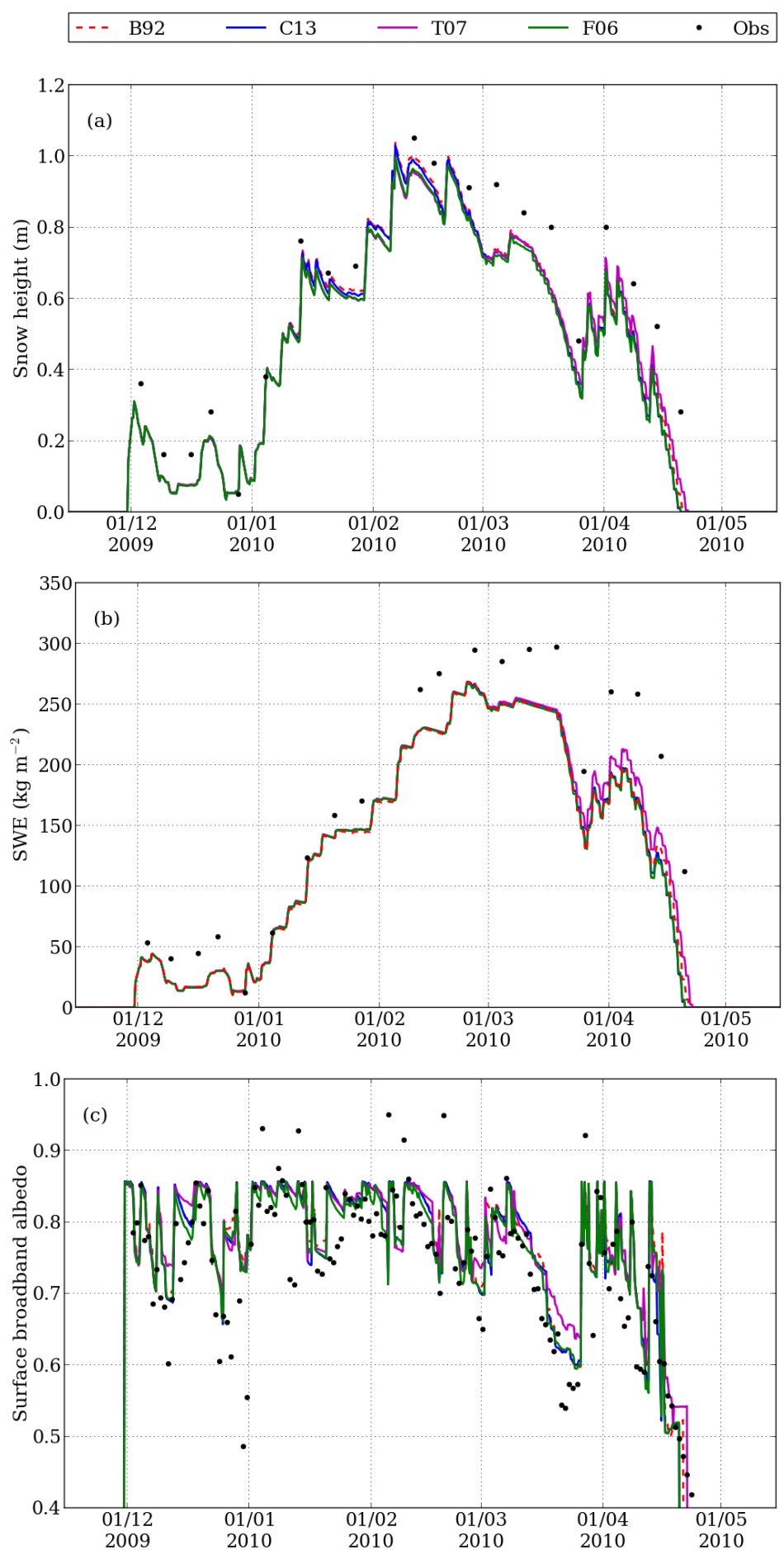

Fig. 2: Snow height (top), SWE (middle) and surface broadband albedo (bottom) at Col de Porte during winter 2009/2010, simulated using four different metamorphism formulations. The black dots in (a) and (b) represent manual weekly measurements and those in (c) represent daily-integrated albedo data. 

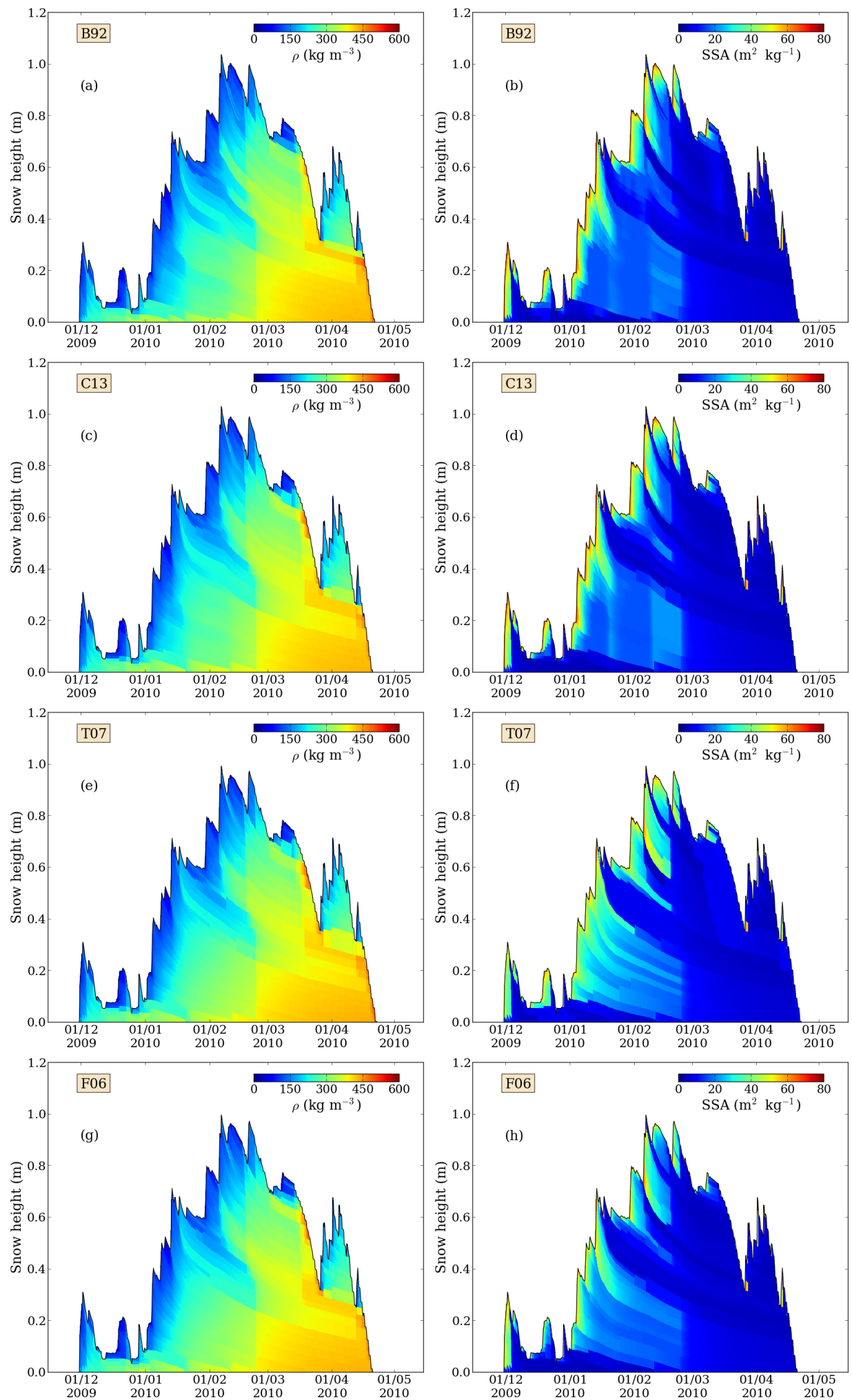

Fig. 3: Simulated density (left column) and SSA (right column) at Col de Porte during winter 2009/2010. Simulations were run using different metamorphism formulations. 

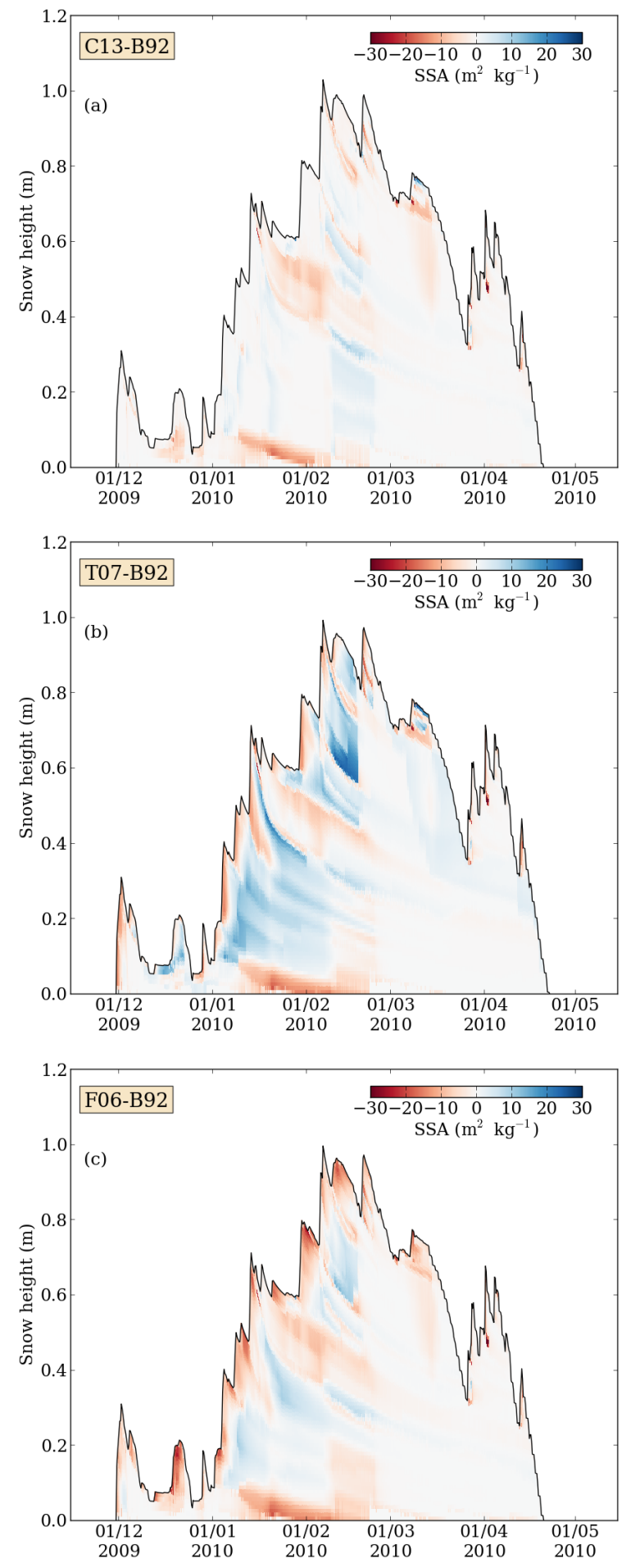

Fig. 4: Comparison in terms of SSA between the metamorphism formulations implemented into Crocus. In order to compare results obtained using different formulations, all SSA profiles were interpolated over a $1 \mathrm{~cm}$ vertical grid. The three plots show the difference between the new formulations C13 (top), T07 (middle) and F06 (bottom) and the original formulation B92, for simulations run at Col de Porte during winter 2009/2010. 

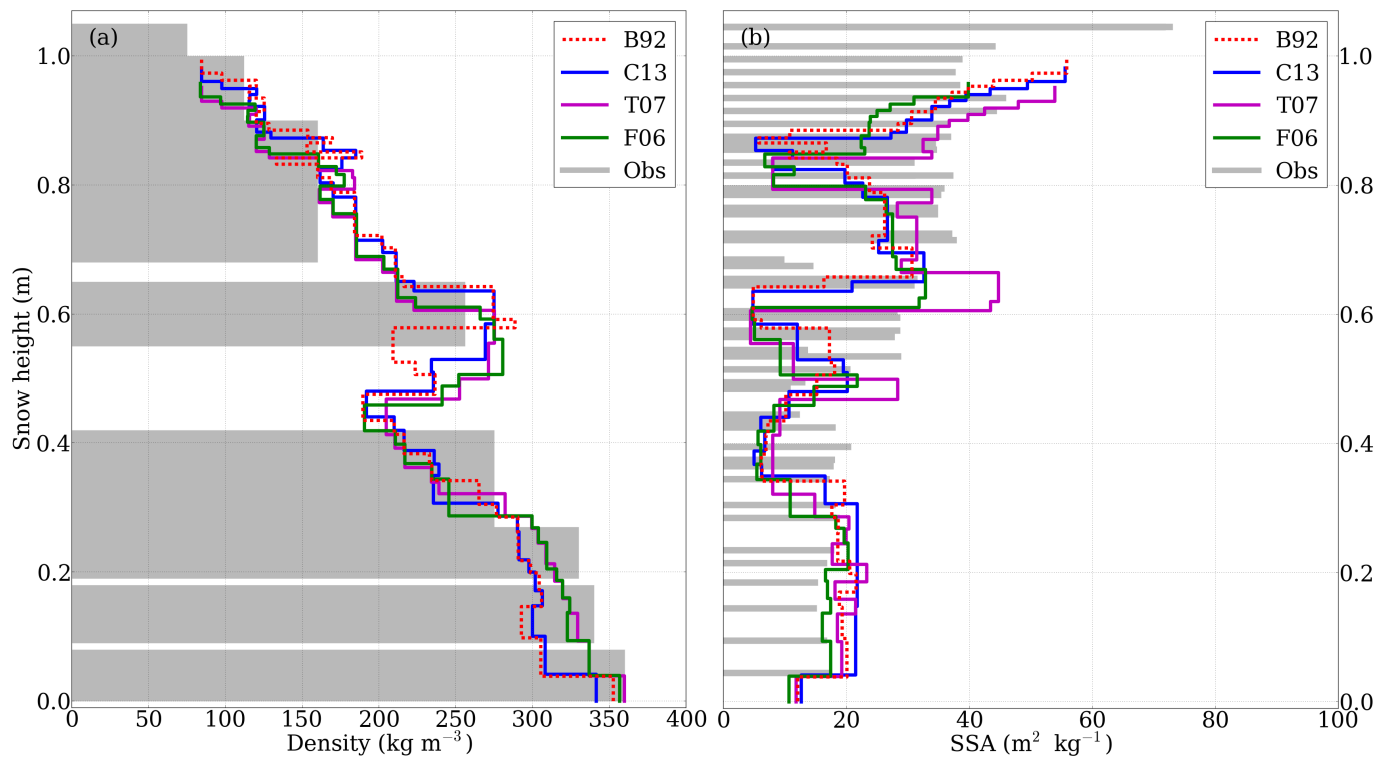

Fig. 5: Comparison between simulated and measured density (left) and SSA (right) at Col de Porte, on 11 February 2010, 12h00 LT. 